\title{
Going public
}

Should scientists let the public help them decide how government research funds are spent? Yes they should, because the consequences are to be welcomed, not feared.

S cience communication, circa 1600: discussions with the public, according to one prominent researcher, are little better than listening to the "maunderings of a babbling hag". So said William Gilbert, a pioneer of research into electricity and magnetism.

Today's scientists are, at least in the main, a more open-minded bunch. But the prejudices and fears that underlie Gilbert's remark have not entirely gone away, as reactions to some new initiatives show.

Take last month's report by Demos, a UK political think-tank. For many researchers, it will make frightening reading. The left-leaning Demos makes the first coherent call for 'upstream engagement' - the involvement of non-specialists in setting research priorities. British scientists have seen the public swayed by misleading media coverage of genetically modified (GM) food and vaccines. For them, the proposal must seem close to giving the lunatics the keys to the asylum.

Such concerns will not be restricted to Britain: environmental organizations across Europe are committed in practice to ending research into GM crops. Some religious groups in the United States would end research involving human embryos if they had the power to do so. And it would be impossible to develop safer and more efficient nuclear power stations, which will probably be needed to tackle climate change, if anti-nuclear groups have too much influence on research policy.

Yet there are good reasons why scientists should ignore these fears and embrace upstream engagement. On an ethical and political level, the research community has no right to reject public involvement outright. Taxpayers fund research, buying themselves the right to help shape its course. Objecting to public involvement would simply undermine the current enthusiasm shown for science funding by some governments, such as those in the United States and Britain.

\section{Balance of power}

There is also plenty of evidence to suggest that upstream engagement, if managed properly, will not bring an end to any area of research. Such engagement is already being quietly and usefully practised in the research-charity sector, where the trustees of many funding organizations are non-scientists. And the slew of new initiatives being proposed for the public sector involve giving the public less power than the trustees, and certainly not a veto over research spending.

When worrying about engagement, British researchers may also be swayed too much by the GM fiasco, in which propaganda put out by environmental groups and the biotechnology industry made public debate extremely difficult. But other exercises have proved less combative and more fruitful. The Natural Environment Research Council, for example, last year ran public consultations on a new research programme. It led to a new theme - the sustainable management of marine bioresources — being added to the programme.

Get the process right, and other consultations could produce equally meaningful input. No one wants to haul people off the street and make decisions based solely on questionnaires. There are numerous mechanisms for engaging the public, from citizens' juries to consensus conferences and deliberative mapping processes. The details vary, but all involve giving non-specialists access to a range of different perspectives on a particular topic, and allowing them to develop their own recommendations through structured discussion. Sociologists say that the techniques need to be evaluated to see which works best, but that's no reason not to start now.

Funding bodies are the obvious target for engagement exercises. In the United States, the National Institutes of Health (NIH) faces increasing lobbying from advocacy groups, often representing the needs of patients with a specific disease, who want the agency to do less basic research and more drug development. Public engagement could help the NIH bolster its efforts to incorporate a broader range of views into its decision-making processes.

\section{Nothing to fear}

In many European nations, there is little call for upstream engagement. But Britain, where a lack of public trust in science is perceived as a serious problem, is a notable exception. Not all of the country's funding bodies have taken this on board. The Biotechnology and Biological Sciences Research Council, which is setting up a permanent committee of non-scientists to advise on strategy, leads the way. But the Engineering and Physical Sciences Research Council (EPSRC) has lagged behind. This is worrying, as the council funds research in nanotechnology, an area of science that could one day transform everything from drug delivery to computing.

Judging by the few consultations that have already been run on nanotechnology, the EPSRC should not fear public involvement. Non-specialists tend to reject the call for a moratorium on nanotech research made by one more extreme environmental group. Instead, they suggest that environmentally useful applications, such as new solar-power systems, should be made more of a priority. More work on the environmental impact of nanoparticles is another common request - a call echoed by July's report on the same topic by the Royal Society and the Royal Academy of Engineering.

Upstream engagement is no panacea. On its own, it won't solve Britain's crisis over trust in science. Nor will it resolve thorny questions about what types of science are worth pursuing, and which should be avoided because of links to technology such as weapons of mass destruction. But it is worth doing — provided that all involved consider two points before beginning.

First, the processes must be long-term and properly funded. Money spent on engagement is often diverted from basic research. So if governments are serious about upstream projects, they should talk to research agencies about how to ring-fence money to run the consultations. In Britain, this is likely to amount to a few million a year across all sciences, a fraction of a per cent of the total science budget.

More importantly, funding organizations must make a genuine commitment to react to the results of engagement processes. This doesn't mean simply accepting the outcomes; research councils should clearly remain in ultimate charge of priority setting. But for the process to be meaningful, funders must explain why they choose to accept some pieces of advice and reject others. The UK government ran a public debate on genetic modification last year and is widely believed to have ignored the results - something only a little less offensive than talking about babbling hags. 